\section{Screening of ESBL Producing Multidrug Resistant E. coli from Urinary Tract Infection Suspected Cases in Southern Terai of Nepal}

\section{Khushbu Yadav ${ }^{1^{*}}$ and Satyam Prakash ${ }^{2}$}

${ }^{1}$ Krishna Medical Technical Research Center, Purbanchal University, Janakpurdham, Nepal

${ }^{2}$ Department of Biochemistry, Janaki Medical College Teaching Hospital, Tribhuvan University, Janakpurdham, Nepal

*Corresponding authors: Khushbu Yadav, Medical Microbiologist and Lecturer, Krishna Medical Technical Research Center, Purbanchal University, Janakpurdham, Nepal, Tel: +977-9841603704; E-mail: meetkhushi20@gmail.com

Received date: August 4, 2017; Accepted date: August 16, 2017; Published date: September 5, 2017

Copyright: (C) 2017 Yadav K, et al. This is an open-access article distributed under the terms of the Creative Commons Attribution License, which permits unrestricted use, distribution, and reproduction in any medium, provided the original author and source are credited.

\begin{abstract}
Background and objectives: Multidrug-resistant E. coli expressing extended-spectrum $\beta$-lactamase pose serious challenges to clinicians for the therapeutic management of clinical cases in urinary tract infection. The ability of beta-lactamase to cause resistance varies with its activity, quantity, cellular location of gram-negative organisms and its permeability of the producer strain. Therefore, this study was focused to determine the dominance of MDR $E$. coli and evaluation of status of $\beta$-lactamase enzyme produced by MDR E. coli.
\end{abstract}

Materials and methods: A total of 321 successive midstream urine samples were processed among suspected cases of urinary tract infection. Standard microbiological techniques were used for isolation and identification of uropathogens. The antimicrobial susceptibility pattern of bacterial isolates was determined by Kirby-Bauer Disc Diffusion technique. The MDR $E$. coli isolates were screened for ESBL by double disc synergy test and confirmed with combined disc diffusion test. The $p$ - value $<0.05$ was considered as statistically significant.

Results: The maximum numbers of MDR E. coli isolates were isolated as of female patients with $55.75 \%$ than male of $44.24 \%$. Most of the MDR E. coli isolates were isolated from less than 20 years with $30.97 \%$ and was dropped in between $40-60$ years with $20.35 \%$. The MDR E. coli isolates in association with gender and age group was found to be statistically insignificant $(p=0.310)$. Among 69 suspected $E S B L E$. coli isolates, $62.31 \%$ were confirmed as ESBL producer.

Conclusion: $E$. coli isolates showed shocking rate of drug resistance to the frequently prescribed drugs. The high rate of ESBL-producing MDR E. coli was also observed. There is an increasing need for periodic monitoring of drug susceptibility pattern to prevent the spread and development of antimicrobial resistant strains and ESBL producers.

Keywords: Escherichia coli; Extended spectrum $\beta$-lactamase; Multidrug resistance; Urinary tract infection

\section{Introduction}

Urinary Tract Infection (UTI) is the commonest bacterial infection prevalent to both female and male. It is expected that about $35 \%$ of healthy women experiences warning signs of UTIs [1]. The incidence is more frequent in women than men due to squatness of female urethra, dearth of prostatic secretions, easy contamination with fecal flora and pregnancy [2]. The dominance of this disease is additional in developing countries owed to deprived sanitation, living method, undernourishment, and ecological stipulation [3]. Mostly, neonates, girls, young women, infants, young children and older men are mainly vulnerable to UTIs [4].

UTIs involves bacterial invasion and multiplication of the pathogen in the organs of the urinary tract system is classified into uncomplicated and complicated infections on the basis of organ involved [5,6]. Infection may be expressed predominantly as pyelonephritis, pyelitis, ureteritis, cystitis, prostitis and urethritis but the entire urinary tract is always at risk of invasion by bacteria [3] Microorganisms belonging to Enterobacteriaceae have been documented as elementary reason of nosocomial and community acquired UTIs [7]. The infinite majority of uncomplicated UTIs are caused by the Gram negative bacilli and with other pathogens including Enterococci, Staphylococcus saprophyticus, Klebsiella spp, Pseudomonas spp, Proteus spp, Staphylococcus aureus and Proteus mirabilis [4].

Numerous studies have barbed towards high incidence rate of UTI associated with $E$. coli and antibiotic resistance. The emergence of Multi Drug Resistant (MDR) variant of $E$. coli has been accounted $[8,9]$. MDR is defined as resistance to at least two antibiotics of different classes including aminoglycosides, chloramphenicol, tetracyclines and/or erythromycin $[10,11]$. MDR in many bacteria is due to the action of multi-drug efflux pumps and by the accumulation on Resistance (R) plasmids or transposons, of genes with each coding for resistance to a specific agent $[10,12]$. Nowadays, in UTIs ExtendedSpectrum Beta-Lactamase-expressing Gram-Negative Bacilli (ESBLGNB) generally cause community-acquired infections [13]. The resistance of Gram-negative bacteria is typically owed to plasmidmediated enzymes called Extended-Spectrum B-Lactamases (ESBLs) [14]. ESBL producing bacteria are typically associated with MDR and antibacterial choice is often complicated by multi-drug resistance [15-17]. 
Extended-spectrum $\beta$-lactamase and metallo $\beta$-lactamase producing bacteria are up-and-coming apprehension for health professionals. Patients with increased threat of increasing colonization or infection with ESBL producing microorganisms are repeatedly fatally sick patients with prolonged hospital stays [18]. They are frequently resistant to numerous antibiotic classes, including fluoroquinolones and aminoglycosides. Resistance to $\beta$-lactam antibiotics has increased significantly in the last two decades and has been documented in both community and hospital settings [19-21]. Current updated knowledge of the susceptibility pattern of bacteria is vital for the appropriate assortment and utilization of antimicrobial drugs and, also for the succession of suitable prescribing guidelines [22]. The infections caused by MDR pathogens, the rate of emergence and spread of antibiotic resistance cannot be reduced without gathering information about the existing MDR strains [23]. Although, ESBL and MBL have been studied well in Nepalese community $[24,25]$ but scanty information has been witnessed related to multi drug resistant variant of $E$. coli reported from the Southern Terai of Nepal. Therefore, this study was designed to isolate and identify the causative agent of UTI, determination of prevalence of MDR among the pathogens and to evaluate the status of $\beta$-lactamase enzyme producer MDR E. coli.

\section{Materials and Methods}

\section{Study design}

The present research work was a hospital based cross-sectional study which was conducted in the Microbiology Unit of Clinical Pathology Laboratory at Janaki Medical College Teaching Hospital (JMCTH), Janakpur, Nepal from April to December, 2014.

\section{Ethical consideration}

Informed consent was attained from the participant and work approval was taken from the institutional ethical committee of JMCTH, Janakpur, Nepal earlier to the study. A term paper of information letter and consent form was prearranged to patients ahead of participating in the research. In case of ignorant and uneducated participants, information was endowed with interpretation of the consent form in presence of eyewitness in the local language. The information of patients such as name, sex, age and clinical history were collected. If the patients were children, the information was gathered related to the subject matter with the help of their parents.

\section{Inclusion and exclusion criteria}

The patient's history with complaint of nausea, micturition, dysuria, polyuria, haematuria, suprapubic tenderness, pain or pressure in back or lower abdomen was included. Those clinical samples which showed poly-microbial and insignificant growth, incomplete culture form, without proper labeling including date, time, age, lab number and sex were excluded.

\section{Specimen collection}

The Mid Stream Urine (MSU) samples (10-20 ml) were collected in the sterile clean dry wide mouthed leak-proof bottle. The idiosyncratic instruction was followed by the patient for the sample collection. The container was then labeled properly with serial no., age and sex. When instantaneous processing was not achievable, the sample was frozen at $4-6^{\circ} \mathrm{C}$, and likely boric acid $(1.8 \% \mathrm{w} / \mathrm{v})$ was added as preservative to the urine with delay of more than $2 \mathrm{~h}$ estimated [26].

\section{Culture of specimen}

Medias were set as instructed by the manufacturer company (Himedia). The urine specimen was streaked on the MacConkey Agar (MA) and Blood Agar (BA) medium by the semi-quantitative culture procedure via a standard loop. After mixing the urine sample in the container methodically, a loopful of sample was contacted to the centre of the plate, from which the inoculum was spread in a line across the diameter of the plate. The loop was drawn across the entire plate devoid of flaming crossing the first inoculum streak abundantly to produce isolated colonies. The plates were incubated aerobically at $37^{\circ} \mathrm{C}$ overnight. The fairly accurate numeral of colonies was count up. The number of bacteria i.e. Colony Forming Unit (CFU) per ml urine anticipated in accordance to the volume of urine inoculated formerly and testimonized as-Less than $10^{4} / \mathrm{ml}$ organisms: not significant, $10^{4}-10^{5} / \mathrm{ml}$ organisms: doubtful significance (suggest repeat specimen) and more than $10^{5} / \mathrm{ml}$ organisms: Significant bacteriuria.

\section{Identification of the isolates}

Detection of significant bacterial isolates were done by using microbiological techniques as illustrated in the Bergy's manual which entails morphological appearance of the colonies, staining reactions and biochemical properties.

\section{Antimicrobial susceptibility testing (AST)}

Antibiotic sensitivity test for the isolated organism were done by using Kirby Bauer Disc Diffusion technique following the definition of the National Committee of Clinical Laboratory Standards [27]. Bacterial inoculums were prepared by suspending the freshly-grown bacteria in $25 \mathrm{ml}$ sterile Nutrient broth. A sterile cotton swab was used to streak the surface of Mueller Hinton agar plates. Filter paper disks restraining designated amounts of the antimicrobial drugs were acquired from commercial supply firms (Himedia Labs, Mumbai, India). Interpretation as 'Sensitive' or 'Resistant' was completed on the base of the diameters of zones of inhibition of bacterial growth as suggested by the disc manufacturer.

After performing the antimicrobial susceptibility testing, MDR isolates in pure culture were preserved in $20 \%$ glycerol containing Tryptic soya broth and kept at $-70^{\circ} \mathrm{C}$ until subsequent tests for the existence of ESBL was completed.

\section{Screening and confirmation for ESBL producers}

The MDR E. coli isolates were screened for possible ESBL producer using ceftazidime $(30 \mu \mathrm{g})$ and cefotaxime $(30 \mu \mathrm{g})$ [27]. According to the guiding principle, isolates showing ceftazidime $<22 \mathrm{~mm}$ and cefotaxime $<27 \mathrm{~mm}$ are the potential ESBL producing strains. The screen positive isolates i.e. suspected ESBL producers were subjected to Combined Disk (CD) test for authentication of ESBL production using MASTDISCSTM Extended Spectrum $\beta$-Lactamase (ESBL) detection discs. The kit consisted of:

Set 1: Ceftazidime $(30 \mu \mathrm{g})$ and ceftazidime $(30 \mu \mathrm{g})$ plus clavulanic acid $(10 \mu \mathrm{g})$

Set 2: Cefotaxime $(30 \mu \mathrm{g})$ and cefotaxime $(30 \mu \mathrm{g})$ plus clavulanic acid $(10 \mu \mathrm{g})$ 
Citation: Yadav K, Prakash S (2017) Screening of ESBL Producing Multidrug Resistant E. coli from Urinary Tract Infection Suspected Cases in Southern Terai of Nepal. J Infect Dis Diagn 2: 116.

Page 3 of 8

\section{Quality control}

Laboratory tools and equipment like refrigerator, incubator, autoclave and hot air oven were routinely monitored for their effectiveness. The temperature of refrigerator and incubator was observed on a daily basis for their performance and instantly corrected if any variations found. Reagents and media were frequently monitored for their manufacture, expiry date and proper storage. After preparation, they were properly labeled with preparation date. The quality of media prepared was ensure by incubating one plate of each lot for sterility and using standard control strains for performance testing. During identification of organisms, for each test Escherichia coli (ATCC 25922), Staphylococcus aureus (ATCC 25923) and Pseudomonas aeruginosa (ATCC 27853) were used as reference strains for culture and sensitivity testing. Strict aseptic conditions were kept up while carrying out all the procedures.

\section{Statistical analysis}

The analysis of data was done by using SPSS 20.0 version and Microsoft Excels 2007. The p-value $<0.05$ was considered statistically significant.

\section{Results}

\section{Prevalence of UTI among suspected respondents}

A total number of patients attending OPD, JMCTH were 321 of which 150 were male and 171 as female. Among them, 202 (62.92\%) had UTI in which $48.01 \%$ were male and $51.98 \%$ female and rest of them were free of UTI. The prevalence of UTI in relation to gender was found to be statistically insignificant $(p=0.985)$. The outcomes are shown in Table 1.

\begin{tabular}{|l|l|l|l|l|}
\hline \multirow{2}{*}{ Gender } & \multicolumn{2}{|l|}{ UTI } & \multirow{2}{*}{$\begin{array}{l}\text { Total OPD } \\
\text { patients }\end{array}$} & Statistics \\
\cline { 2 - 3 } & Positive & Negative & & \\
\cline { 2 - 4 } & No. (\%) & No. (\%) & & \\
\hline Male & $97(48.01)$ & $53(44.53)$ & 150 & \multirow{2}{*}{$\begin{array}{l}x^{2}=0.364 \\
p=0.985\end{array}$} \\
\hline Female & $105(51.98)$ & $66(55.46)$ & 171 & \\
\hline Total & $202(62.92)$ & $119(37.07)$ & 321 & \\
\hline
\end{tabular}

Table 1: Microbial growth among the total suspected patients.

\begin{tabular}{|c|c|c|c|c|}
\hline \multirow{2}{*}{$\begin{array}{l}\text { Age group } \\
\text { (yrs) }\end{array}$} & \multicolumn{2}{|l|}{ Gender } & \multirow{2}{*}{$\begin{array}{l}\text { Total bacterial } \\
\text { growth (\%) }\end{array}$} & \multirow[t]{2}{*}{ Statistics } \\
\hline & Male (\%) & Female (\%) & & \\
\hline$<20$ & 19 (19.58) & $22(20.95)$ & $41(20.29)$ & \multirow{5}{*}{$\begin{array}{l}x^{2}=1.152 \\
p=0.997\end{array}$} \\
\hline $20-40$ & $46(43.80)$ & $47(48.45)$ & $93(46.03)$ & \\
\hline $40-60$ & $27(27.83)$ & $29(27.61)$ & $56(27.72)$ & \\
\hline$>60$ & $4(4.12)$ & $8(7.61)$ & $12(5.94)$ & \\
\hline Total & $97(48.01)$ & 105 (51.98) & 202 & \\
\hline
\end{tabular}

Table 2: Bacterial growth among positive UTI respondents.

\begin{tabular}{|l|l|l|l|}
\hline Antibiotic used & Sensitive & Intermediate & Resistant \\
\cline { 2 - 4 } & No. (\%) & No. (\%) & No. (\%) \\
\hline Imipenem & $77(62.60)$ & $20(16.26)$ & $26(21.13)$ \\
\hline Doxicycline & $39(31.70)$ & $33(26.82)$ & $51(41.46)$ \\
\hline Norfloxacin & $29(23.57)$ & $13(10.56)$ & $81(65.85)$ \\
\hline Cephalexin & $9(7.31)$ & $17(13.82)$ & $97(78.86)$ \\
\hline Nitrofurantoin & $54(43.90)$ & $4(3.25)$ & $64(52.03)$ \\
\hline Ciprofloxacin & $29(23.57)$ & $22(17.88)$ & $72(58.53)$ \\
\hline Cotrimoxazole & $21(17.07)$ & $14(11.38)$ & $88(71.54)$ \\
\hline Amikacin & $75(60.97)$ & $28(22.76)$ & $20(16.26)$ \\
\hline Ofloxacin & $31(25.20)$ & $13(10.56)$ & $79(64.22)$ \\
\hline Nalidixic Acid & $6(4.87)$ & $26(21.13)$ & $91(73.98)$ \\
\hline Ceftazidime & $32(26.01)$ & $13(10.56)$ & $78(63.41)$ \\
\hline Ceftriaxone & $29(23.57)$ & $11(8.94)$ & $83(67.47)$ \\
\hline
\end{tabular}

Table 3: Antibiotic susceptibility pattern of $E$. coli.

\section{Age and gender wise distribution of significant bacterial growth}

Among total positive UTI respondents, the significant growth of bacterial isolates were observed more in between 20-40 years age of $46.03 \%$ followed between $40-60$ years $(27.72 \%)$ and less than 20 years (20.29\%). Visible bacterial growth was found lesser in above 60 years. In almost all age groups, female's urine specimen showed highest bacterial growth than male. The relation between the age and gender wise pattern of bacterial isolates were found statistically insignificant $(\mathrm{p}=0.997)$ as shown in Table 2.

\section{Microbial profile of urinary isolates isolated from respondents}

A total of 202 bacterial isolates were identified in which 123 isolates were $E$. coli, 27 were $K$. pneumoniae, 3 were $P$. aeruginosa, 38 were $P$. vulgaris, 4 were $S$. aureus and 7 were $C$. diversus. Among all bacterial isolates, $E$. coli was found to be major micro-organism to cause UTI. The results are revealed in Figure 1.

\section{Antibiotic susceptibility pattern of $E$. coli}

Of 12 different antibiotics used against 123 E. coli isolates, imipenem was found to be the drug of choice with the susceptibility of $62.60 \%$ chased by amikacin with $60.97 \%$ and nitrofurantoin with $43.90 \%$ but cephalexin and nalidixic acid was observed least effective drug which showed the highest resistance with $78.86 \%$ and $73.98 \%$ respectively. The results are depicted in Table 3.

\section{Age and gender wise distribution of MDR $E$. coli}

Among 123 E. coli isolates, 113 were MDR E. coli strains. The highest figures of bacterial isolates were found in female patients with $55.75 \%$ than male of $44.24 \%$. Most of the MDR E. coli strain was isolated from less than 20 years with $30.97 \%$ and drop was observed in 
Citation: Yadav K, Prakash S (2017) Screening of ESBL Producing Multidrug Resistant E. coli from Urinary Tract Infection Suspected Cases in Southern Terai of Nepal. J Infect Dis Diagn 2: 116.

Page 4 of 8

between $40-60$ years with $20.35 \%$. The MDR E. coli isolates in association with gender and age group was found to be statistically insignificant $(\mathrm{p}=0.310)$. The results are as given in Table 4 .

\section{ESBL production of MDR $E$. coli}

A total of 123 E. coli isolates were isolated, of which 113 were MDR strains where 69 isolates were suspected as ESBL producers. Among suspected cases, the total numbers of confirmed cases were 43 $(62.31 \%)$ as shown in Table 5.

\section{Screening for ESBL production of MDR E. coli}

Of the total 113 MDR E. coli isolates, 69 MDR E. coli isolates suspected as producers of $\beta$-lactamases were screened for ESBL production using ceftazidime and ceftriaxone as the CLSI suggested screening agents. The sensitivity and positive prediction value of Ceftazidime was more than Cefotaxime. There were significant association between ESBL production with ceftazidime and cefotaxime as shown in Table 6.

\section{Patterns of ESBL production confirmed by combination disks assay}

Of 43 screened ESBL $E$. coli isolates were subjected for ESBL confirmation test using different combination disks with ceftazidimeclavulanate and cefotaxime-clavulanate in which all the screened cases were established as ESBL positive as shown in Table 7.

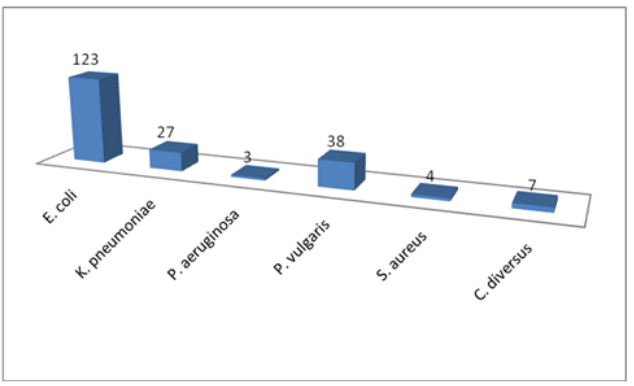

Figure 1: Frequency pattern of total microbial isolates.

\begin{tabular}{|c|c|c|c|c|}
\hline \multirow{2}{*}{$\begin{array}{l}\text { Age groups } \\
\text { (years) }\end{array}$} & \multicolumn{2}{|l|}{ Gender } & \multirow{2}{*}{$\begin{array}{l}\text { Total MDR E. } \\
\text { coli }\end{array}$} & \multirow[t]{2}{*}{ Statistics } \\
\hline & Male (\%) & Female (\%) & & \\
\hline$<20$ & $13(26)$ & $22(34.92)$ & $35(30.97)$ & \multirow{5}{*}{$\begin{array}{l}x^{2}=9.387 \\
p=0.310\end{array}$} \\
\hline $20-40$ & $8(16)$ & $19(30.15)$ & $27(23.89)$ & \\
\hline $40-60$ & $10(20)$ & $13(20.63)$ & $23(20.35)$ & \\
\hline$>60$ & $19(38)$ & $9(14.28)$ & $28(24.77)$ & \\
\hline Total & $50(44.24)$ & $63(55.75)$ & 113 & \\
\hline
\end{tabular}

Table 4: Pattern of MDR E. coli isolated from total respondents.

\begin{tabular}{|l|l|l|l|l|l|l|}
\hline Organism & Total isolates (\%) & $\begin{array}{l}\text { No. of } \\
\text { Strains (\%) }\end{array}$ & $\begin{array}{l}\text { No. of suspected ESBL } \\
\text { production (\%) }\end{array}$ & $\begin{array}{l}\text { No. of cases confirmed } \\
\text { (\%) }\end{array}$ & $\begin{array}{l}\text { Negative cases on } \\
\text { confirmation (\%) }\end{array}$ \\
\hline E. coli & $123(38.31)$ & $113(91.86)$ & $69(61.06)$ & $43(62.31)$ & $26(37.68)$ \\
\hline
\end{tabular}

Table 5: MDR E. coli produces $\beta$ - lactamases.

\begin{tabular}{|c|c|c|c|c|c|c|}
\hline Screening agent & $\begin{array}{l}\text { ESBL screening of } \\
\text { suspected cases }\end{array}$ & & $\begin{array}{l}\text { No. of confirmed ESBL } \\
\text { producer }\end{array}$ & Sensitive (\%) & $\begin{array}{l}\text { Positive predictive value } \\
(\%)\end{array}$ & Statistics \\
\hline \multirow[t]{2}{*}{ Ceftazidime $(30 \mu \mathrm{g})$} & Screen positive & 44 & 38 & \multirow[t]{2}{*}{88.37} & \multirow[t]{2}{*}{86.36} & \multirow{2}{*}{$\begin{array}{l}x^{2}=29.89 \\
p=0.000\end{array}$} \\
\hline & Screen negative & 25 & 5 & & & \\
\hline \multirow[t]{2}{*}{ Cefotaxime $(30 \mu \mathrm{g})$} & Screen positive & 49 & 36 & \multirow[t]{2}{*}{83.72} & \multirow[t]{2}{*}{73.46} & \multirow{2}{*}{$\begin{array}{l}x^{2}=7.70 \\
p=0.005\end{array}$} \\
\hline & Screen negative & 20 & 7 & & & \\
\hline
\end{tabular}

Table 6: Screening for ESBL production of MDR E. coli.

\begin{tabular}{|c|c|c|c|c|c|}
\hline Combination disks assay & Criteria for confirmation & $\begin{array}{l}\text { No. of suspected } \\
\text { ESBL }\end{array}$ & $\begin{array}{l}\text { No. of } \\
\text { confirmed } \\
\text { cases }\end{array}$ & $\begin{array}{l}\text { Total } \\
\text { confirmed } \\
\text { cases }\end{array}$ & $\begin{array}{l}\text { Negative cases } \\
\text { after confirmation }\end{array}$ \\
\hline $\begin{array}{l}\text { CAZ }(30 \mu \mathrm{g}) \text { and CAZ }(30 \mu \mathrm{g}) \text { plus } \\
\mathrm{CV}(10 \mu \mathrm{g})\end{array}$ & & & 43 & & \\
\hline $\begin{array}{l}\text { CAZ }(30 \mu \mathrm{g}) \text { and CTX }(30 \mu \mathrm{g}) \text { plus } \\
\text { CV }(10 \mu \mathrm{g})\end{array}$ & $\begin{array}{l}\text { Increase zone size of }>5 \mathrm{~mm} \text { with }>1 \text { of the } \\
\text { combination disks }\end{array}$ & 69 & 43 & 43 & 26 \\
\hline
\end{tabular}

Table 7: Confirmation of ESBL by combination disks. 


\section{Discussion}

UTIs are generally widespread nosocomial infection in Nepal [28]. UTI is associated with alterations in the host's systemic or local immunity, such as immune-suppression, diabetes, hyperadrenocorticism, anatomic abnormalities (polyps/tumors, recessed vulva), indwelling catheters, uroliths, or urethral sphincter mechanism incompetence. E. coli are considered as a normal component of gastrointestinal and distal urogenital flora, but it can ascend the urethra and gain entrance to the urinary tract. Specific virulence factors found in E. coli allow it to adhere to and invade host cells, produce toxins, utilize host nutrients, and evade the host's immune system $[29,30]$.

The present study enrolled 321 suspected UTI patients where $62.92 \%$ suffered from UTIs in which $48.01 \%$ were male and $51.98 \%$ female. Similar type of study conducted by Chaudhari et al. found $25.60 \%$ were male and $74.40 \%$ were female [31]. Both study showed the higher prevalence of UTI take place in female. The probable reasons for UTI in young women may be due to short urethra and its opening, complex physiology especially during gestational period. Additionally, certain variety of contraceptives can also encourage the peril of UTIs $[4,32]$.

The present study depicts that the age grouping of 20-40 years had the highest visible bacterial growth and least growth was observed above 60 years. Amongst the isolates, the highest integer of pathogens was isolated from sample of female patients (51.98\%) as compared to male $(48.01 \%)$. Similar result was reported in the study conducted at National Public Health Laboratory, Teku, Kathmandu, Nepal by Thakur et al. [33]. These parallel results are in concord with earlier studies [32,34-36]. This may be due to the incidence of UTI increases with age and sexual activity. Vast majority of acute symptomatic infections involve young women. But, in contrast Thakur et al. noted high prevalence of UTI in old age in male subjects [33] which may be exceptional to diverse circumstances like prostatitis, diabetes, pathetic immune status and past antibiotic treatments in associated diseases.

This study reports 202 bacterial isolates were identified in which 123 isolates were $E$. coli, 27 were $K$. pneumoniae, 3 were $P$. aeruginosa, 38 were $P$. vulgaris, 4 were $S$. aureus and 7 were $C$. diversus. Among all bacterial isolates, $E$. coli was found to be predominant organism to cause UTI. The study accomplished at Microbiology Department of National College, Kathmandu, Nepal by Yadav et al. observed that of 25 samples showing significant bacteriuria were caused by $E$. coli (84\%) whereas Citrobacter diversus, Klebsiella pneumoniae and Staphylococcus aureus with 16\% [4]. Nalini and Sumathi found 356 E. coli, 123 Pseudomonas spp, 73 Klebsiella spp and 54 Proteus spp were identified in their study [37]. Similarly, Wadekar et al. reported E. coli (67.7\%) was the most universal isolate followed by Staphylococcus and Klebsiella spp [38]. Out of 367 urine samples processed in the study organized by Kulkarni et al. yielded 96 were E. coli and 58 were Klebsiella species [39]. Chaudhari et al. isolated bacterial pathogen from UTIs as E. coli (66\%), Klebsiella spp. (12\%), Enterococcus spp. (8\%), Pseudomonas spp. (6\%), Acinetobacter anitratus (5\%), and Proteus spp. (3\%) [31].

Likewise, a study conducted by Yadav and Prakash in 2015 at Microbiology Unit, Clinical pathology laboratory in the collaboration with Medicine department at Janaki Medical College Teaching Hospital, Janakpur, Nepal also noted the highest number of $E$. coli isolates involved in UTI among diabetics [32]. Shrestha et al. reported in 2016, E. coli $(71.3 \%), K$. pneumoniae $(9.8 \%), K$. oxytoca $(8.6 \%)$,
Proteus spp. (4.6\%), C. fruendi (2.3\%), Pseudomonas spp. (1.7\%), Enterobacter spp. (1.1\%) and Acinetobacter spp. (0.6\%) isolates from UTIs [7]. Chaudhary et al. found in their study $67 \%$ and $18 \%$ of infection was produced by E. coli and Staphylococcal species respectively and others were Klebsiella, Citrobacter and Pseudomonas spp [40]. Mishra et al. reported E. faecalis, $S$. aureus, $C$. freundii, $E$. aerogenes, E. coli, $K$. oxytoca, $K$. pneumoniae, $P$. vulgaris and $P$. aeruginosa were isolated from UTI patients [41]. Parajuli et al. accounted E. coli (68.4\%) leading pathogen involved in UTI [42].

From all the above study, E. coli was the major pathogen concerned with UTI. As E. coli is a common pathogen which is usually a commensal bacterium of humans. Intestinal and extra-intestinal infections, including gastroenteritis, urinary tract infection, meningitis, peritonitis, and septicemia are caused by pathogenic variants [43]. E. coli have unique virulent properties that can bind to Gal alpha1-4 Gal receptor of the uroepithelial cells of human urinary tract which can commence infectivity itself and contributory to a foremost uropathogen throughout the world [44]. The attachment of Proteus species to uroepithelial cells instigate the secretion of interleukin 6 and interleukin 8 in the mucosal endothelial cells and induces apoptosis and epithelial cell desquamation. Urease production, in concert with the attendance of bacterial motility and fimbriae, may errand the fabrication of upper urinary tract infections by Proteus spp. [45]. Patients who are on ventilators, catheters or surgery wounds are highly prone to catching Hospital-acquired infection by Klebsiella spp. [46].

Antimicrobial resistance is now recognized as an increasingly global problem, especially in Gram-negative bacteria [47]. UTIs are mainly treated with $\beta$-lactam antibiotics. However, acquired resistance to these antibiotics in UTI pathogens is commonly augmented by bacterial enzymes, and leads to the emergence of ESBLs [48]. In this study, 12 different antibiotics used against $123 \mathrm{E}$. coli isolates in which cephalexin, nalidixic acid, cotrimoxazole, ceftriaxone and ceftazidime showed the highest resistivity with $78.86 \%, 73.98 \%, 71.54 \%, 67.47 \%$ and $63.41 \%$ respectively. But, the study conducted by Perez et al. accounted $94 \%$ E. coli isolates to be resistant to ceftriaxone [49]. This high rate of resistance may be due to the lack of antibiotic policy and the irrational use of third generation cephalosporins, mainly ceftriaxone in the hospital [50]. E. coli was highly resistant to ciprofloxacin $(81 \%)$ which is analogous with this study conducted by Haque and Salam [51].

Increasing resistance to broad spectrum cephalosporins amongst $E$. coli and Klebsiella species predominantly due to the production of ESBLs were accounted from several countries $[52,53]$. The established fact is that the increased level of drug resistance seen among $E$. coli is mediated by $\beta$-lactamases, which hydrolyze the $\beta$-lactam ring inactivating the antibiotic, the classical TEM-1, TEM-2, and SHV-1 enzymes are the predominant plasmid-mediated $\beta$-lactamases of gram-negative rods [10,48]. Furthermore, self-medication practice, easy availability of drugs from pharmacy, its use without doctor's prescription and loopholes in guidelines in drug policy in developing countries like Nepal might be a prime cause of antimicrobial resistance.

This study signifies that the antibiotic susceptibility pattern of E. coli showed that imipenem, amikacin and nitrofurantoin was the most effective drug. Also, similar results had seen documented in previous studies $[31,33]$ which are in accordance with this study. Amikacin was developed from kanamycin to chunk the access of a diversity of kanamycin-modifying enzymes to their target sites [54]. Among the 
various aminoglycoside-modifying enzymes, Acetyltransferases (AAC $\left(6^{\prime}\right)$-I and AAC (6')-APH (2')), Adenyltransferases (ANT (4')-I and ANT (4')-II), and Phosphotransferases (APH (3')-II and APH (3')-III) have been revealed to upshot in the modification of amikacin [55] which demonstrates a reasonably high prevalence of amikacin susceptibility which is typically pragmatic among members of the family Enterobacteriaceae. The advanced vulnerability of $E$. coli to nitrofurantoin may be prejudiced by nitrofurantoin's narrow spectrum of activity, inadequate indication, narrow tissue distribution and limited contact with bacteria outside the urinary tract [56].

This study highlights that $E$. coli showed the predominant number of MDR strains (91.86\%). Higher rate of MDR was found in female patients $(55.75 \%)$ compared to male $(44.24 \%)$. The outcomes of this study are similar to Thakur et al. [33].

Problems in UTIs have been augmented because of the occurrence of ESBL producing $E$. coli due to overuse of third generation cephalosporins and monobactams [57]. The present study noted 69 MDR E. coli isolates that were suspected of being producers of $\beta$ lactamases were screened for ESBL. Among suspected cases, $62.31 \%$ were found as confirmed cases. Shrestha reported high prevalence of MDR E. coli (65.0\%) isolates were ESBL positive [58]. This rate is similar to additional studies that accounted as 40-70\% [33,39,59-70]. Kashyap et al. in 2013 reported the prevalence of ESBLs production was 37\% [71] which correlates with Kumar et al. in 2006 and Jalalpour in 2011 [72,73]. But, the study conducted by Hazir et al. noted only $23.56 \%$ ESBL prevalence in $E$. coli which is analogous result reported by another study $[74,75]$. This is not in accord with the present study because of disparity in geographical variation and study design.

\section{Conclusion}

The present study highlights the therapeutic future of the $\beta$-lactam antibiotics is serious dilemma and gigantic challenge to clinicians. Nowadays, UTIs caused by ESBL-producing E. coli has emerged more rigorously. Therefore, early identification of infections due to this pathogen is essential for rapid establishment of appropriate treatment and to reduce the mortality in hospital and community setting. In order to prevent and control the emergence of antimicrobial resistance in ESBL producing organisms, it is of utmost importance to edge the misuse and overuse of antibiotics especially broad spectrum antibiotics. Further, the recognition of antimicrobial resistance and more specifically towards $\beta$-lactam drugs should be routinely surveyed and monitored at different time interval. These findings also suggest integrating early and sensitive methods to detect ESBL producing strains should be practiced so that appropriate antibiotics can be used. It is also important to formulate appropriate community as well as hospital antibiotic policies to decrease the spread of ESBL producing microorganisms. Moreover, researches are desirable for finding novel drugs and their rational use in coming future.

\section{Limitation}

The study was carried out in only one hospital of this area which does not reveal the cyclic, geological and tribal difference of pathogens and their antibiotic susceptibility profile picture of the whole country. The genotype of ESBLs among $E$. coli isolates was not detected due to lack of feasibility of time duration and resources available in the laboratory.

\section{Acknowledgement}

The authors debt their heartily gratitude to hospital staffs and especially to Mr. Raj Narayan Yadav, Mr. Buddhiram Yadav and Mr. Ganga Ram Shrestha including all members of clinical pathology laboratory, Janaki Medical College Teaching Hospital (JMCTH), Janakpur, Nepal for their consistent support towards this work.

\section{Author's Contribution}

KY-Concept and design of study, inscription of manuscript and descriptive data analysis, and final approval of manuscript. SPReviewed literatures and involved in scripting first draft of manuscript, revision of final manuscript with critical intellectual content.

\section{Source of Support}

All the logistic supports were provided by Janaki Medical College teaching Hospital, Janakpur, Nepal.

\section{Conflict of Interest}

None declared.

\section{References}

1. Rezwana H, Laila A, Abdus S (2015) Prevalence and susceptibility of uropathogens: a recent report from a teaching hospital in Bangladesh. Biomed Cen Res Notes 8: 416.

2. Nithyalakshmi J (2014) Bacterial profile and antibiogram pattern of UTI in pregnant women at tertiary care teaching hospital. Int J Pharm Bio Sci 5: 201-207.

3. Cheesbrough M (2000) District laboratory practice in tropical countries. Cambridge Univ press 2: 125-137.

4. Yadav K, Prakash S, Serayi RC, Shilpkar T, Shrestha S (2014) Antimicrobial susceptibility test of pathogens isolated from urinary tract infection suspected cases. Janaki Med Coll J Med Sci 2: 28-34.

5. Iroha I, Nwakeze E, Ejikeugwu C, Oji A, Udu-Ibiam E, et al. (2013) Frequency and antibiogram of uropathogens isolated from urine samples of HIV infected patients on antiretroviral therapy. Am J Bio Sci 1: 50-53.

6. Forouzan MZA, Amir B (2013) Prevalence and antimicrobial susceptibility patterns of uropathogens among patients referring to Valieasr laboratory in Najafabad, Isfahan, Iran. Middle-East J Sci Res 13: 85-90.

7. Shrestha A, Manandhar S, Pokharel P, Panthi P, Chaudhary KD (2016) Prevalence of Extended Spectrum Beta-Lactamase (ESBL) producing multidrug resistance gram-negative isolates causing urinary tract infection. EC Microbiol 4: 749-755.

8. Sharma AR, Bhatta DR, Shrestha J, Banjara MR (2013) Antimicrobial susceptibility pattern of Escherichia coli isolated from urinary tract infected patients attending Bir hospital. Nepal J Sci Tech 14: 177-184.

9. Tansarli GS, Athanasiou S, Falagasa ME (2013) Evaluation of antimicrobial susceptibility of Enterobacteriaceae causing urinary tract infections in Africa. Antimicrob. Agents Chemother 57: 3628-3639.

10. Yadav K, Prakash S (2016). Antimicrobial resistance (AMR): A global problem. Glob J Publ Health Epidemiol 3: 120-138.

11. Huys G, Cnockaert M, Vaneechoutte M, Woodford N, Nemec A, et al. (2005) Distribution of tetracycline resistance genes in genotypically related and unrelated multiresistant Acinetobacter baumannii strains from different European hospitals. Resist Microbiol 156: 348-355.

12. Nikaido H (2009) Multidrug resistance in bacteria. Ann Review Biochem 78: 119-146.

13. Dotis J, Printza N, Marneri A, Gidaris D, Fotios Papachristou F (2013) Urinary tract infections caused by extended-spectrum $\beta$-lactamase- 
producing bacteria in children: a matched case control study. Turkish J Pediatr 55: 571-577.

14. Livermore DM (2008) Defining an extended-spectrum beta-lactamase. Clin Microbiol Infect 14: 3-10.

15. Araj GF, Samaha-Kfoury JN (2003) Recent developments in $\beta$-lactamases and extended spectrum $\beta$-lactamases. BMJ 327: 1209-1213.

16. Shah AA, Hasan F, Ahmed S, Hameed A (2004) Extended spectrum betalactamases (ESBLs): characterization, epidemiology and detection. Crit Rev Microbiol 30: 25-32.

17. Rupp ME, Fey PD (2003). Extended-spectrum beta-lactamase (ESBL) producing Enterobacteriaceae: considerations for diagnosis, prevention and drug treatment. Drug 63: 353-365.

18. Paterson DL, Bonomo RA (2005) Extended-spectrum $\beta$-lactamases: a clinical update. Clin Microb Rev 18: 657-686.

19. Osthoff M, McGuinness SL, Wagen AZ, Eisen DP (2015) Urinary tract infections due to extended-spectrum beta lactamase- producing gramnegative bacteria: Identification of risk factors and outcome predictors in an Australian tertiary referral hospital. Int J Infect Dis 34: 79-83.

20. Hammami S, Saidani M, Ferjeni S, Aissa I, Slim A, et al. (2013) Characterization of extended spectrum B-lactamase-producing Escherichia coli in community-acquired urinary tract infections in Tunisia. Microb Drug Resist 19: 231-236.

21. Cantas L, Suer K, Guler E, Imir T (2016) High emergence of ESBLproducing E. coli cystitis: time to get smarter in Cyprus. Front Microbio 6: 1446

22. Ahmed AA, Osman H, Mansour AM (2000) Antimicrobial agent resistant in bacterial isolates from patients with diarrhea and urinary tract infection in Sudan. Am J Trop Med Hyg 63: 259-263.

23. Tuladhar NR, Banjade N, Pokhrel BM (2004) Comparative study of multi-drug resistant bacterial strains of respiratory pathogens among in and out patients of Tribhuvan University Teaching Hospital, Kathmandu Nepal. JNAMLS 6: 19-24.

24. Pokharel BM, Koirala J, Mishra SK, Dahal RK, Khadga P, et al. (2006) MDR and ESBL producing strains causing lower respiratory tract and urinary tract infections. J Inst Med 28: 19-27.

25. Poudyal S (2010) Prevalence of $\beta$-lactamase producing multidrug resistant bacterial pathogens isolated from different clinical samples at National Public Health Laboratory. M.Sc. Dissertation submitted to Central Department of Microbiology, Tribhuvan University 5-74.

26. Forbes BA, Sahm DF, Weissfeld AS (2007) Bailey and Scotts diagnostic microbiology (12th Ed.). Elesvier USA 514-618.

27. Clinical and Laboratory Standards Institute (CLSI) (2015) Performance standards for antimicrobial susceptibility testing. USA: CLSI: M100-S25 Wayne, PA.

28. Kattel HP, Acharya J, Mishra SK, Rijal BP, Pokhrel BM (2008) Bacteriology of urinary tract infection among patients attending Tribhuvan University Teaching Hospital, Kathmandu, Nepal. J Nepal Assoc Med Lab Sci 9: 25-29.

29. Kate SK (2011) Managing the E coli UTI. Consultant Call NAVC Clinician’s Brief 61-66.

30. Asadi S, Kargar M, Solhjoo K (2014) The association of virulence determinants of uropathogenic escherichia coli with antibiotic resistance, Jundishapur. J Microb 7: 1-5.

31. Chaudhari KB, Singh KG, Parajuli PK, Shrestha K (2016) Incidence and susceptibility of uropathogens isolated among the patients at tertiary care hospital in Eastern Nepal. J Nobel Med Coll 5: 51-55.

32. Yadav K, Prakash S (2016) Antimicrobial resistance pattern of uropathogens causing Urinary Tract Infection (UTI) among diabetics. Biomed Res Int 1: 7-15.

33. Thakur S, Pokhrel N, Sharma M (2013) Prevalence of multidrug resistant Enterobacteriaceae and extended spectrum $\beta$ lactamase producing Escherichia coli in urinary tract infection. Res J Pharm Biol Chem Sci 4: 1617-1624.

34. Bomjan R (2005) Prevalence of multidrug resistant strains with reference to Extended-spectrum $\beta$-lactamase producing strains among the bacterial pathogens isolated from different clinical samples at Tribhuvan University Teaching Hospital. M.Sc. Dissertation submitted to the Central Department of Microbiology, Tribhuvan University, Kathmandu, Nepal.

35. Gupta S (2010) Prevalence of multidrug resistant uropathogens isolated from Ohm hospital Nepal. M.Sc. Dissertation submitted to the Central Department of Microbiology, Tribhuvan University, Kathmandu, Nepal.

36. Livermore DM, Hawkey PM (2005) CTX-M: changing the face of ESBLs in the UK. J Antimicrob Chemother 56: 451-454.

37. Nalini K, Sumathi P (2012) Detection of ESBL and cephalosporinase in urinary tract isolates. J Pharmaceutical Biomedical Sci 21: 1-5.

38. Wadekar DM, Jagdish L, Rani NBS, Gupta KR (2016) Extended spectrum $\beta$ lactamase producing Escherichia coli in urinary tract infections tip-off to evaluate treatment practice. Indian J Microbiol Res 3: 175-179.

39. Kulkarni DM, Bardapurkar SA, Nilekar SL, More SR (2016) Prevalence of extended spectrum $\beta$-lactamase (ESBL) producing E. coli and Klebsiella species in urinary isolates. IOSR J Dent Med Sci 15: 26-29.

40. Chaudhary V, Sharma G, Chaudhary N, Raghuvanshi RK (2016) High prevalence of multiple drug resistance among pediatric Escherichia Coli infections. Int J Med Res Health Sci 5: 166-169.

41. Mishraa PM, Sarangib R, Padhya NR (2016) Prevalence of multidrug resistant uropathogenic bacteria in pediatric patients of a tertiary care hospital in Eastern India. J Infec Pub Health 9: 308-314.

42. Parajuli PN, Maharjan P, Parajuli H, Joshi G, Paudel D, et al. (2017) High rates of multidrug resistance among uropathogenic Escherichia coli in children and analyses of ESBL producers from Nepal. Antimicrob Resist Infect Control 6: 1-7.

43. Von Baum H, Marre R (2005) Antimicrobial resistance of Escherichia coli and therapeutic implications. Int J Med Mocrobiol 295: 503-511.

44. Ko KS, Suh JY, Peck KR, Lee MY, Oh WS, et al. (2007) In vitro activity of fosfomycin against ciprofloxacin-resistant or extended-spectrum $\beta$ lactamase-producing Escherichia coli isolated from urine and blood. Diagn Microbiol Infect Dis 58: 111-115.

45. http://emedicine.medscape.com/article/226434-overview\#a5

46. Boston Medical Research Occupational Health Program (2010).

47. Slama TG (2008) Gram-negative antibiotic resistance: there is a price to pay. Crit Care 12: 1-7.

48. Pitout JDD, Laupland KB (2007) Extended spectrum beta lactamase producing Enterobacteriaceae: an emerging public health concern. Lancet Infect Dis 8: 159-166.

49. Perez F, Endimiani A, Hujer KM, Bonomo RA (2007) The continuing challenge of ESBLs. Curr Opin Pharmacol 7: 459-469.

50. Shobha KL, Gowrish RS, Sugandhi R, Sreeja CK (2007) Prevalence of extended spectrum beta lactamases in urinary isolates of Escherichia coli, Klebsiella and Citrobacter species and their antimicrobial susceptibility pattern in tertiary care hospital. Ind J Pract Doct 3: 1-2.

51. Haque R, Salam MA (2010) Detection of ESBL producing nosocomial gram negative bacteria from a tertiary care hospital in Bangladesh. Pak J Med Sci 26: 887-891.

52. Bouchillon SK, Johnson BM, Hoban DJ, Johnson JL, Dowzicky MJ, et al. (2004) Determining incidence of extended spectrum beta-lactamase producing Enterobacteriaceae, vancomycin-resistant Enterococcus faecium and methicillin-resistant Staphylococcus aureus in 38 centres from 17 countries: the PEARLS study 2001-2002. Int J Antimicrob Agents 4: 119-124.

53. Khanfar HS, Bindayna KM, Senok AC, Botta GA (2009) Extended spectrum beta-lactamases (ESBL) in Escherichia coli and Klebsiella pneumoniae: trends in the hospital and community settings. J Infect Dev Ctries 3: 295-299.

54. Kondo S, Hotta K (1999) Semisynthetic aminoglycoside antibiotics: development and enzymatic modifications. J Infect Chemother 5: 1-9.

55. Shaw KJ, Rather RS, Hare RS, Miller GH (1993) Molecular genetics of aminoglycoside resistance genes and familial relationships of the aminoglycoside-modifying enzymes. Microbiol Rev 57: 138-163.

56. James AK, Laurie J, Clyde T (2002) Trends in antimicrobial resistance among urinary tract infection isolates of Escherichia coli from female 
Citation: Yadav K, Prakash S (2017) Screening of ESBL Producing Multidrug Resistant E. coli from Urinary Tract Infection Suspected Cases in Southern Terai of Nepal. J Infect Dis Diagn 2: 116.

Page 8 of 8

outpatients in the United States. Antimicrob Agents Chemother 46: 2540-2545.

57. Paterson DL, Yu VL (1999) Extended spectrum beta lactamases: a call for improved detection and control. Clin Infect Dis 29: 419-422.

58. Shrestha B, Tada T, Shrestha S, Katte HP, Ohara H, et al. (2015) Coexistence of aminoglycosides and $\beta$-lactam-resistant Escherichia coli phenotypes in a Tertiary care center of Nepal. J Inst Med 37: 65-73.

59. Sharma S, Bhat GK (2007) Virulence factors and drug resistance in Escherichia coli isolated from extraintestinal infection. Ind $\mathrm{J}$ Med Microbiol 25: 369-373.

60. Goyal A, Prasad KN, Prasad A, Gupta S, Ghosal U, et al. (2009) Extended-spectrum $\beta$-lactamases in Escherichia coli and Klebsiella pneumonia \& associated risk factors. Indian J Med Res 129: 695-700.

61. Hussain M, Hasan F, Shah AA, Hameed A, Jung M, et al. (2011) Prevalence of class A and AmpC $\beta$-lactamases in clinical Escherichia coli isolates from Pakistan Institute of Medical Science, Islamabad, Pakistan. Japanese J Infect Dis 64: 249-252.

62. Jabeen K, Zafar A, Hasan (2005) Frequency and sensitivity pattern of extended spectrum beta lactamase producing isolates in a tertiary care hospital laboratory of Pakistan. J Pak Medi Assoc 55: 436-439.

63. Ullah F, Malik SA, Ahmed J (2009) Antibiotic susceptibility pattern and ESBL prevalence in nosocomial Escherichia coli from urinary tract infections in Pakistan. Afr J Biotechnol 8: 3921-3926.

64. Mohammed A, Mohammed S, Asad K (2007) Etiology and antibiotic resistance patterns of community-acquired urinary tract infections in J N M C Hospital Aligarh, India. Ann Clin Microbiol Antimicrob 6: 17.

65. Kadar AA, Angamathu K (2005) Extended-spectrum beta-lactamases in urinary isolates of Escherichia coli, Klebsiella pneumoniae and other gram-negative bacteria in a hospital in Eastern Province, Saudi Arabia. Saudi Med J 26: 956-959.

66. Bouchillon SK, Johnson BM, Hoban DJ, Johnson JL, Dowzicky MJ, et al. (2002) Interscience conference. Antimicrob Agents Chemother 42: 27-30.
67. Supriya ST, Suresh VJ, Sarfaraz A, Umesh H (2004) Evaluation of extended spectrum beta lactamases in urinary isolates. Ind J Med Res 120: 553-556.

68. Dalela G, Gupta S, Jain KD, Mehta P (2012) Antibiotic resistance pattern in uropathogens at a tertiary care hospital at Jhalawar with special reference to ESBL, AMP C $\beta$-lactamases \& MRSA production. J Clin Diag Res 6: 645-651.

69. Rajan S, Prabavathy V (2012) Antibiotic sensitivity and phenotypic detection of ESBL producing E.coli strains causing UTI in a community hospital Chennai, Tamil Nadu, India. Webmed Central Pharm Sci 3: 1-17.

70. Singhal S, Mathur T, Khan S, Upadhyay DJ, Chugh S, et al. (2005) Evaluation of methods for AMP C $\beta$-lactamase in gran negative clinical isolates from a tertiary care hospital. Ind J Med Microbiol 23: 120-124.

71. Kashyap G, Gupta S, Mamoria PV, Durlabhji P, Jain D (2013) Increasing prevalence of extended spectrum beta lactamases (ESBLs) producing E. coli and Klebsiella spp in outpatient departments (OPDs) patients in urinary tract infections (UTIs) in tertiary care hospital. Int J Curr Res Rev 5: 80-86.

72. Kumar MS, Lakshmi V, Rajagopalan R (2006) Occurrence of extendedspectrum $\beta$-lactamases among Enterobacteriaceae ssp. isolated at a tertiary care institute. Ind J Med Microbiol 24: 208-211.

73. Shila J (2011) Survey frequency of extended spectrum beta-lactamases (ESBLs) in Escherichia coli and Klebsiella pneumonia strains isolated from urinary tract infection in Iran. Afr J Microbiol Res 5: 3711-3715.

74. Ibukun A, Tolu O, Brian JM (2003) Extended-spectrum $\beta$-lactamases in isolates of Klebsiella spp and Escherichia coli from Lagos, Nigeria. Nig J Health Biomed Sci 2: 53-60.

75. Shafiq M, Rahman H, Qasim M, Ayub N, Hussain S, et al. (2013) Prevalence of plasmid-mediated ampC $\beta$-lactamases in Escherichia coli and Klebsiella pneumoniae at tertiary care hospital of Islamabad, Pakistan. Euro J Microbiol Immunol 4: 267-271. 